\title{
A MED13-dependent skeletal muscle gene program controls systemic glucose homeostasis and hepatic metabolism
}

\author{
Leonela Amoasii, ${ }^{1,2,3}$ William Holland, ${ }^{4}$ Efrain Sanchez-Ortiz, ${ }^{1,2,3}$ Kedryn K. Baskin, ${ }^{1,2,3}$ \\ Mackenzie Pearson, ${ }^{4}$ Shawn C. Burgess, ${ }^{5,6}$ Benjamin R. Nelson, ${ }^{1,2,3}$ Rhonda Bassel-Duby, ${ }^{1,2,3}$ \\ and Eric N. Olson ${ }^{1,2,3}$ \\ ${ }^{1}$ Department of Molecular Biology, University of Texas Southwestern Medical Center, Dallas, Texas 75390, USA; ${ }^{2} \mathrm{Hamon}_{\text {Center }}$ \\ for Regenerative Science and Medicine, University of Texas Southwestern Medical Center, Dallas, Texas 75390 , USA; ${ }^{3}$ Senator \\ Paul D. Wellstone Muscular Dystrophy Cooperative Research Center, University of Texas Southwestern Medical Center, Dallas, \\ Texas 75390, USA; ${ }^{4}$ Department of Internal Medicine, University of Texas Southwestern Medical Center, Dallas, Texas 75390, \\ USA; ${ }^{5}$ Advanced Imaging Research Center, University of Texas Southwestern Medical Center, Dallas, Texas 75390, USA; \\ ${ }^{6}$ Department of Pharmacology, University of Texas Southwestern Medical Center, Dallas, Texas 75390, USA
}

The Mediator complex governs gene expression by linking upstream signaling pathways with the basal transcriptional machinery. However, how individual Mediator subunits may function in different tissues remains to be investigated. Through skeletal muscle-specific deletion of the Mediator subunit MED13 in mice, we discovered a gene regulatory mechanism by which skeletal muscle modulates the response of the liver to a high-fat diet. Skeletal muscle-specific deletion of MED13 in mice conferred resistance to hepatic steatosis by activating a metabolic gene program that enhances muscle glucose uptake and storage as glycogen. The consequent insulin-sensitizing effect within skeletal muscle lowered systemic glucose and insulin levels independently of weight gain and adiposity and prevented hepatic lipid accumulation. MED13 suppressed the expression of genes involved in glucose uptake and metabolism in skeletal muscle by inhibiting the nuclear receptor NURR1 and the MEF2 transcription factor. These findings reveal a fundamental molecular mechanism for the governance of glucose metabolism and the control of hepatic lipid accumulation by skeletal muscle. Intriguingly, MED13 exerts opposing metabolic actions in skeletal muscle and the heart, highlighting the customized, tissue-specific functions of the Mediator complex.

[Keywords: glucose homeostasis; mediator complex; skeletal muscle; NURR1/NR4A2]

Supplemental material is available for this article.

Received October 7, 2015; revised version accepted December 29, 2015.

Mediator is a multiprotein complex that links signaldependent transcription factors and other transcriptional regulators with the basal transcriptional machinery (Malik and Roeder 2010; Taatjes 2010; Allen and Taatjes 2015). There are 26 subunits within the core of the Mediator complex. In addition, the kinase submodule, consisting of MED12, MED13, CDK8 and Cyclin C, serves as a modulator of the activity of the core Mediator complex. The kinase submodule can repress the Mediator by blocking its association with RNA polymerase II (Pol II) (Tsai et al. 2013) and can also enhance transcription by the thyroid hormone receptor (TR) by promoting Pol II recruitment to TR-dependent genes in a context-dependent manner (Kornberg 2005; Furumoto et al. 2007; Belakavadi and Fondell 2010).

Corresponding author: eric.olson@utsouthwestern.edu Article is online at http://www.genesdev.org/cgi/doi/10.1101/gad.273128. 115 .
Through physical interactions between various transcription factors, nuclear receptors, and specific Mediator subunits, the Mediator complex controls different signaling pathways and processes. Recent studies have begun to reveal unexpected specificity with which various Mediator subunits influence metabolism. For example, MED1, a core Mediator subunit, binds to nuclear receptors, and its deletion in skeletal muscle enhances metabolism (Chen et al. 2010; Jia et al. 2014). Additional components of the Mediator complex are involved in fatty acid, cholesterol, and lipid homeostasis (Yang et al. 2006; Zhao et al. 2012; Tsai et al. 2013; Chu et al. 2014). We reported that cardiac overexpression of MED13 increases energy consumption and confers a lean phenotype in mice /Grueter

(C) 2016 Amoasii et al. This article is distributed exclusively by Cold Spring Harbor Laboratory Press for the first six months after the full-issue publication date (see http://genesdev.cshlp.org/site/misc/terms.xhtml). After six months, it is available under a Creative Commons License (Attribution-NonCommercial 4.0 International), as described at http:// creativecommons.org/licenses/by-nc/4.0/. 
et al. 2012; Baskin et al. 2014). However, the functions of MED13 in other tissues have not been explored.

As the major tissue in the body and a site for glucose uptake and glycogen storage, skeletal muscle plays a fundamental role in the control of systemic energy metabolism (Mootha et al. 2003; Izumiya et al. 2008; Meng et al. 2013). Sensitization of skeletal muscle to insulin signaling represents a potential means of normalizing glucose homeostasis and metabolism under conditions of obesity and type 2 diabetes (T2D). The liver also modulates glucose homeostasis by producing glucose during periods of fasting, thereby preventing hypoglycemia and maintaining brain function and survival (Oosterveer and Schoonjans 2013). Impaired glucose uptake in skeletal muscle during obesity and T2D results in hepatic steatosis, a rising health concern (Ranalletta et al. 2007; Turner et al. 2013). Enhanced skeletal muscle metabolism and exercise reduce the incidence of metabolic syndrome, T2D, and hepatic steatosis (Izumiya et al. 2008; Egan and Zierath 2013; Meng et al. 2013). Therefore, a better understanding of the molecular mechanisms that regulate muscle energy homeostasis may reveal new strategies for metabolic control.

Here, we show that MED13 governs insulin sensitivity, glucose uptake, and glycogen storage in skeletal muscle by repressing the activity of the nuclear receptor NURR1 and the MEF2 transcription factor, thereby dampening the expression of numerous metabolic genes. The absence of MED13 in skeletal muscle promotes glucose uptake and storage, sensitizing muscle to insulin action and preventing hyperinsulinemia and hepatic steatosis. These findings expose a transcriptional regulatory mechanism for the control of skeletal muscle glucose homeostasis controlled by MED13 and its repressive effect on NURR1 and MEF2. Genetic manipulation of this transcriptional circuit in skeletal muscle evokes long-range effects on systemic energy homeostasis, thereby modulating the response of the liver to a high-fat diet (HFD).

\section{Results}

Muscle-specific deletion of MED13 improves glucose tolerance on a HFD

To explore the functions of MED13 in skeletal muscle, we deleted a conditional "floxed" Med13 allele (Grueter et al. 2012) in mice by breeding with the Myo-Cre mouse line (Li et al. 2005), which expresses Cre recombinase specifically in skeletal muscle (referred to as MED13-mKO mice). Muscle-specific deletion of Med13 exons 7 and 8 (Supplemental Fig. S1A) results in a frameshift and loss of a majority of the MED13-coding sequence, including the nuclear localization sequence, nuclear receptorbinding motifs, leucine zipper, and FoxO-like domain. Med13 depletion did not affect the expression level of other Mediator subunits (Supplemental Fig. S1B).

On a normal chow (NC) diet, MED13-mKO and control (CTL) mice displayed similar body weight, body composition, muscle fiber type composition, and glucose tolerance (Supplemental Fig. S2A-F,K). MED13-mKO and CTL mice also had similar exercise performance and lac- tate release when subjected to voluntary wheel running and treadmill experiments (Supplemental Fig. S2G-J).

After 12 wk of a HFD, MED13-mKO and CTL mice showed similar weight gains and body composition (Fig. 1A,B). However, MED13-mKO mice showed enhanced glucose tolerance relative to CTL littermates (Fig. 1C). In insulin tolerance tests, the MED13-mKO mice also showed improved glucose clearance (Fig. 1D). Serum-free fatty acid analyses were similar between MED13-mKO and CTL mice (Fig. 1E). Serum glucose analyses in the fasted state were also similar between MED13-mKO and CTL mice on a NC diet; however, serum glucose levels were significantly lower in MED13-mKO mice than in CTL mice on a HFD (Fig. 1F). As expected, obesity in response to a HFD led to hyperinsulinemia in CTL mice (Fig. 1G). However, serum insulin levels of MED13mKO mice on a HFD were significantly lower than in CTL mice (Fig. 1G). Thus, although MED13-mKO mice gained weight similar to CTL mice on a HFD, they displayed improved glucose tolerance and protection from hyperinsulinemia.

\section{Skeletal muscle deletion of MED13 prevents hepatic steatosis}

HFD-induced obesity leads to triglyceride (TG) accumulation in the liver. To determine whether improved glucose tolerance and reduced insulin levels affected the response of the liver to a HFD, we analyzed liver TG accumulation by Oil Red O staining. MED13-mKO mice displayed a dramatic reduction in hepatocyte TG accumulation compared with CTL mice on a HFD (Fig. 2A). Biochemical measurements confirmed a pronounced $70 \%$ decrease in TG levels in livers from MED13-mKO mice compared with CTL mice on a HFD (Fig. 2B). To assess whether the decrease in TG accumulation influenced the hepatic glycogen storage response, we measured liver glycogen content. Hepatic glycogen content was similar between MED13-mKO and CTL mice (Supplemental Fig. S3). The reduced liver TG accumulation in MED13-mKO mice on a HFD suggested that MED13 acts within skeletal muscle to modulate hepatic lipid handling.

To determine whether changes in activity, food intake, or body temperature might account for the resistance of MED13-mKO mice to hepatic TG accumulation, we used metabolic cages to monitor the mice on a HFD. MED13-mKO mice and CTL mice showed similar activity, food intake, heat production, $\mathrm{O}_{2}$ consumption, and $\mathrm{CO}_{2}$ production (Supplemental Fig. S4). Additionally, MED13-mKO mice showed no difference in adipocyte size, fat deposition, or the expression of markers of browning, thermogenesis, or adipogenesis in white adipose tissue (WAT) or brown adipose tissue (BAT) (Supplemental Fig. S5). These results suggest that MED13 deletion in skeletal muscle decreases free fatty acid uptake and de novo lipogenesis in the liver, leading to protection from hepatic steatosis independent of adipose tissues.

Reduced hepatic TG accumulation could result from decreased fatty acid import, diminished de novo fatty acid lipogenesis, increased fatty acid oxidation, or 
A

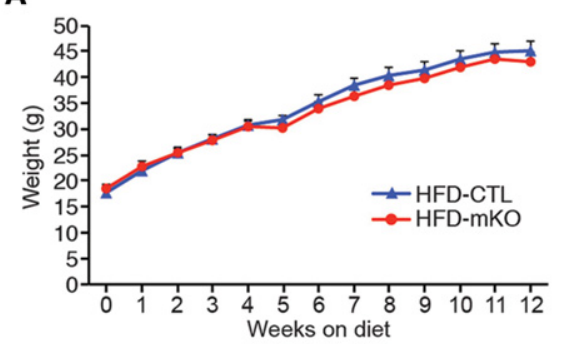

C

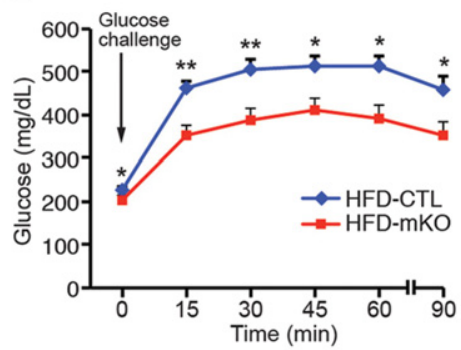

E

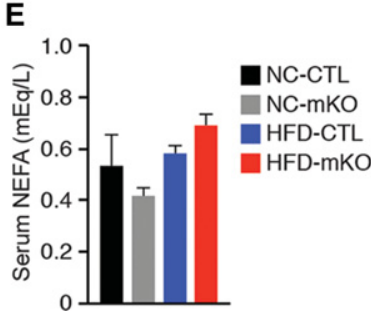

B

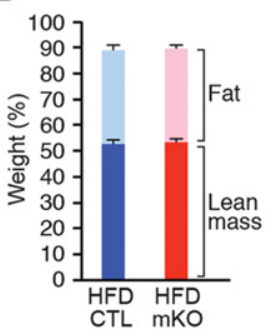

D
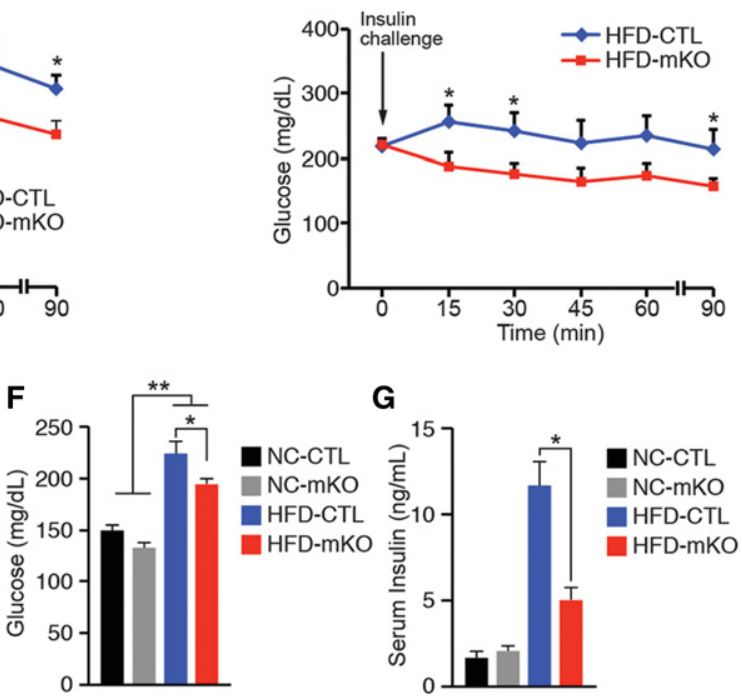

G

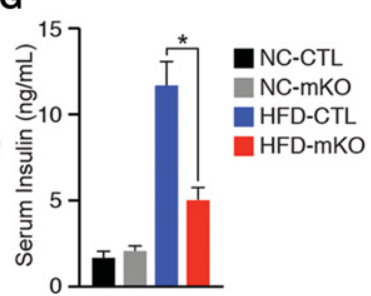

Figure 1. Glucose tolerance and insulin sensitivity of MED13-mKO and CTL mice. (A) Body weights of mice on a HFD for 12 wk. $(B)$ Body composition of mice measured by nuclear magnetic resonance (NMR) after $12 \mathrm{wk}$ on a HFD. (C) Glucose tolerance test measured after 8 wk on a HFD. $n=10 .(D)$ Insulin tolerance test measured after 10 wk on a HFD. $n=10$. (E) Serum nonessential fatty acid levels (NEFA) after 12 wk on a HFD in a post-pandrial state. $(F)$ Serum glucose levels after $12 \mathrm{wk}$ on a HFD in a fasted state. (G) Serum insulin levels after $12 \mathrm{wk}$ on a HFD in a postpandrial state. Data are represented as mean \pm SEM. $n=16$ for a HFD for all experiments unless otherwise stated. $\left(^{*}\right) P<0.05$; $\left({ }^{* *}\right) P<0.005$. enhanced very-low-density lipoprotein-mediated TG export (Brown and Goldstein 2008; Denechaud et al. 2008; Choi and Ginsberg 2011; Moon et al. 2012). To determine which of these pathways might be altered in MED13-mKO mice, we analyzed the expression profile of selected metabolic genes in the liver. The free fatty acid transporter CD36/FAT and fat-specific protein 27 (Fsp27), a lipid droplet-associated protein, were up-regulated in CTL mice under HFD conditions, as reported previously (Fig. 2C; Inoue et al. 2005; Buque et al. 2010). In contrast, both genes were down-regulated in livers from MED13-mKO mice on a HFD (Fig. 2C). As expected, genes involved in fatty acid biosynthesis, cholesterol synthesis, and glycolysis were up-regulated in the livers of CTL mice on a HFD compared with mice on a NC diet (Fig. 2D). In contrast, expression of these genes was significantly decreased in the livers of MED13-mKO mice (Fig. 2D). A modest decrease in the expression of genes involved in $\beta$-oxidation of fatty acids was also seen in MED13-mKO mice on a HFD compared with CTL mice on a HFD (Supplemental Fig. S6A).

In order to functionally assess changes in liver metabolism, we analyzed mitochondrial energetics in isolated hepatic mitochondria using the Seahorse extracellular flux analyzer. Under basal conditions, in the presence of substrates pyruvate and malate, hepatic mitochondria from MED13-mKO mice displayed a modest increase in oxygen consumption rates (OCRs) and in the response to rotenone, succinate, antimycin A, ascorbate, and tetrapheny- lenediamine (TMPD) treatments (Supplemental Fig. S6B). These experiments demonstrate that hepatic mitochondria from MED13-mKO mice contain fully intact and functional electron transport chains and exhibit a moderate increase in mitochondrial respiratory capacity in response to a variety of substrates.

Taken together, our results suggest that Med13 deletion in skeletal muscle decreases free fatty acid uptake and de novo lipogenesis in the liver, leading to protection from hepatic steatosis independent of adipose tissues. These observations also point toward a MED13-dependent signaling pathway that mediates metabolic communication between skeletal muscle and the liver.

\section{Enhanced glucose metabolism in MED13-mKO mice}

In spite of their similar body weights and adiposity, the MED13-mKO mice displayed improved glucose tolerance and insulin responsiveness compared with CTL mice. To quantify peripheral insulin sensitivity and evaluate the effect of insulin action on muscle, adipose tissue, and the liver under matched conditions, we performed hyperinsulinemic-euglycemic clamp studies on MED13-mKO and CTL mice on a HFD diet (Ayala et al. 2006; Kim 2009). The glucose infusion rate required for maintaining euglycemia, a measure of whole-body insulin sensitivity, was substantially higher in MED13-mKO compared with CTL mice (Fig. 3A). In addition, the insulin-stimulated glucose disposal rate was higher in MED13-mKO mice, 
A
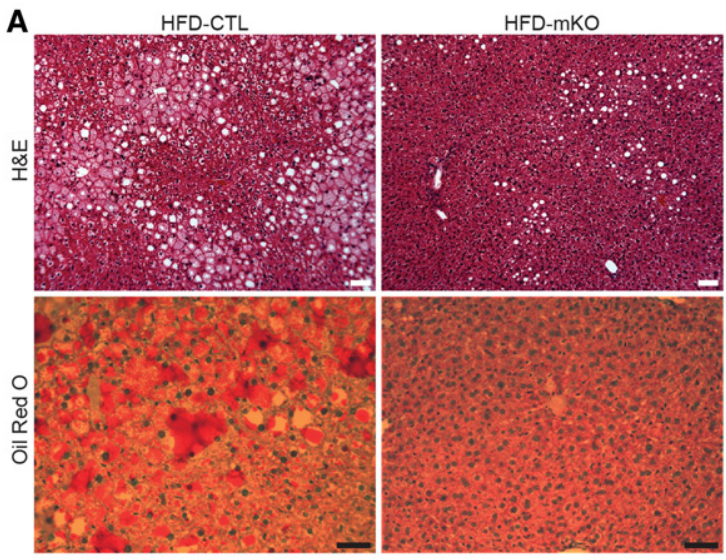

\section{B}

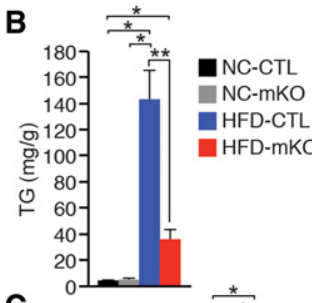

c
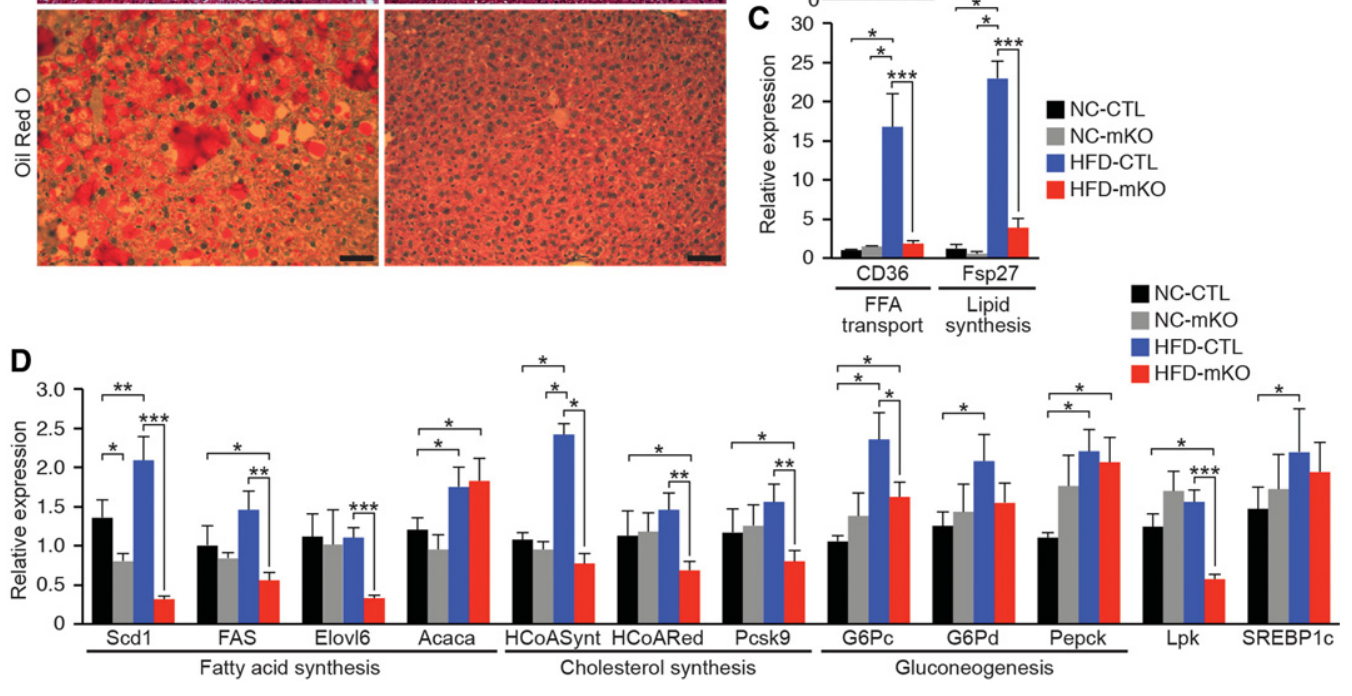

Figure 2. MED13-mKO mice are protected from HFD-induced hepatic steatosis. (A) H\&E and lipid (Oil Red O) stain of liver tissue from mice on a HFD for $12 \mathrm{wk}$. Bar, $50 \mu \mathrm{m}$. (B) Liver TG levels. (C) Real-time quantitative RT-PCR (qRT-PCR) of genes involved in fatty acid transport (CD36/FATP) and synthesis (Fsp27) in liver tissue. (D) Real-time qRT-PCR of genes involved in fatty acid biosynthesis (stearoylCoA destaurase [Scd1], fatty acid synthase [Fas], elongation of long chain fatty acid family member [Elovl6], and acetyl-CoA carboxylase a [Acaca]), cholesterol synthesis (HMG-CoA-synthase [HCoASynt], HMG-CoA-reductase [HCoARed], and proprotein convertase subtilisin/kexin type 9 [Pcsk9]), and gluconeogenesis (glucose 6-phosphatase c [G6Pc], glucose 6-phosphatase d [G6Pd], and liver-type pyruvate kinase $[L p k])$ and sterol regulatory element-binding transcription factor 1c (SREBP1c) in liver tissue. Data are represented as mean \pm SEM. $n=10$ for all experiments unless otherwise stated. $(*) P<0.05 ;\left(^{* *}\right) P<0.005 ;\left(^{* * *}\right) P<0.0005$.

suggesting markedly improved muscle insulin sensitivity (Fig. 3B). Tissue-specific glucose uptake into skeletal muscle was also dramatically higher in MED13-mKO mice than in CTL mice (Fig. 3E), whereas glucose uptake into WAT (Fig. 3E) and hepatic glucose production (Fig. 3D) were unaffected by MED13 loss in muscle. Such differences could not be explained by differences in body weight, circulating insulin, or blood glucose during the clamped state.

To measure glycogen synthesis in muscle, we measured glycogen content in muscle biopsies from the hyperinsulemic-euglycemic clamp study. Remarkably, our results show a twofold increase in newly synthesized glycogen in muscle of MED13-mKO mice compared with CTL mice on a HFD (Fig. 3C). Similarly, in the fed state, muscle from MED13-mKO mice displayed an increase in glycogen content compared with CTL mice on a HFD (Fig. 3F). Histological (Supplemental Fig. S7A) and biochemical (Supplemental Fig. S7B) analyses showed no difference in TG content between MED13-mKO and CTL muscle. There were also no significant differences detected in the lipid content of MED13-mKO and CTL muscle on a HFD or NC diet, as measured by untargeted lipidomics (Supplemental Fig. S8).
To gain further insight into mitochondrial substrate utilization in skeletal muscle, we used $\left[\mathrm{U}^{13} \mathrm{C}_{6}\right]$-glucosebased metabolic flux analysis in vivo. Analysis of quadriceps, gastrocnemius plantaris muscle, and the liver showed no difference in the accumulation of ${ }^{13} \mathrm{C}$-enriched TCA cycle intermediates between CTL and MED13-mKO mice on either a NC diet or HFD (Supplemental Fig. S9). These findings were in agreement with measurements of $\mathrm{O}_{2}$ consumption and $\mathrm{CO}_{2}$ production during metabolic cage experiments (Supplemental Fig. S4E,F) and suggested that glucose oxidation was similar between CTL and MED13-mKO mice in HFD conditions.

Overall, these results suggest that Med13 deletion in skeletal muscle enhances glucose metabolism by increasing glucose uptake and disposal and increasing glycogen storage. This insulin-sensitizing effect improves the whole-body insulin response and renders the liver protected from hepatic steatosis.

\section{Metabolic pathways modified by MED13 deletion in skeletal muscle}

Given the impact of muscle deletion of Med13 on the liver, as indicated by prevention of hepatic steatosis, we 


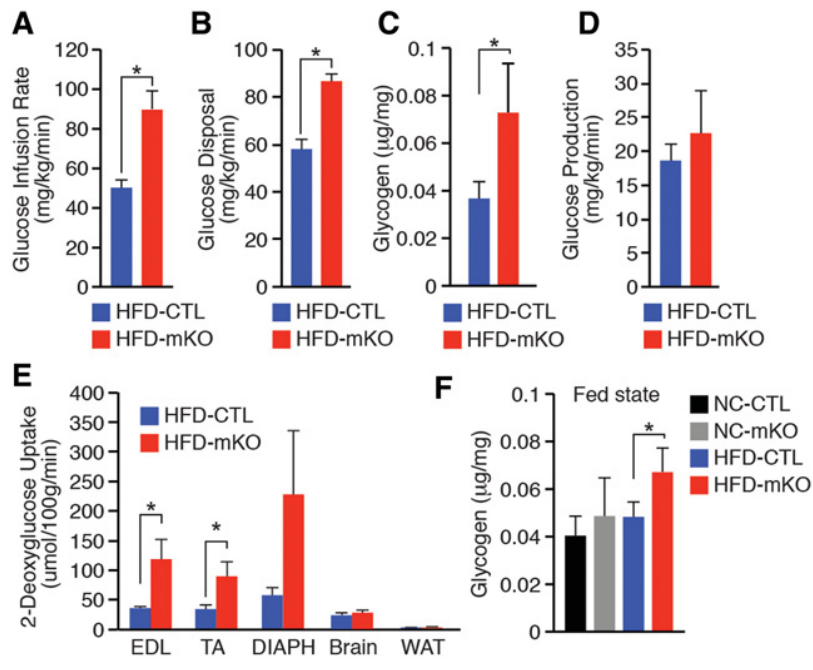

Figure 3. MED13-mKO mice display enhanced skeletal muscle glucose metabolism. Hyperinsulinemic-euglycemic clamp studies performed on mice on a HFD for $8 \mathrm{wk}(n=5$ per group) measured whole-body glucose infusion rate $(A)$, glucose disposal $(B)$, glycogen content in tibialis anterior $(C)$, hepatic glucose production $(D)$, and glucose uptake $(E)$ in skeletal muscle (extensor digitorum longus $[\mathrm{EDL}]$, tibialis anterior $[\mathrm{TA}]$, and diaphragm [DIAPH]), the brain, and WAT using ${ }^{3} \mathrm{H}$-2-deoxyglucose tracer. $(F)$ Glycogen content in quadriceps in the fed state. $n=5$. Data are represented as mean \pm SEM. $\left(^{*}\right) P<0.05$.

analyzed the expression of secreted myokines, such as irisin, interleukin-6, and several members of the FGF family (Supplemental Fig. S10). MED13-mKO muscle showed no significant changes in expression of any of these musclederived regulators of metabolism, pointing to a distinct mechanism of systemic metabolic regulation by skeletal muscle.
Gene expression profiles generated by RNA sequencing (RNA-seq) revealed that carbohydrate metabolism and small molecule transport gene networks were substantially changed in muscle of MED13-mKO mice on a HFD compared with CTL mice on a HFD (Fig. 4A). Specifically, 76 differentially expressed genes were identified in muscle of MED13-mKO mice on a HFD compared with CTL mice on a HFD (Supplemental Fig. S11A, red circle). These 76 genes were divided into four groups: (1) 31 genes that changed only in muscle of MED13-mKO mice in response to a HFD (Supplemental Fig. S11B, listed in the top panel, red), (2) 21 genes that changed in muscle of MED13-mKO mice independently of dietary conditions (Supplemental Fig. S11B, listed in the middle panel, gray), (3) 22 genes that changed in muscle in both MED13-mKO and CTL mice in response to a HFD (Supplemental Fig. S11B, listed in the bottom panel, blue), and (4) two genes that changed under all conditions (Supplemental Fig. S11A).

Validation of RNA-seq data confirmed that numerous genes involved in metabolic processes, including glucose and glycogen metabolism, were up-regulated in muscle of MED13-mKO mice on a HFD compared with CTL mice on a HFD (Fig. 4B). Among these were the nuclear receptor Nurr1 (nuclear receptor subfamily 4 group A member 2 [Nr4a2]), which has been implicated in metabolic control, and salt-inducible kinase 1 (Sik1), which activates MEF2-dependent transcription (Fig. 4B; Supplemental Fig. S11B, top panel).

\section{MED13 regulates Nurr1 expression in skeletal muscle}

Gene expression profiling showed that Nurr1 was upregulated approximately fourfold in skeletal muscle of MED13-mKO versus CTL mice on a HFD (Fig. 4B), which

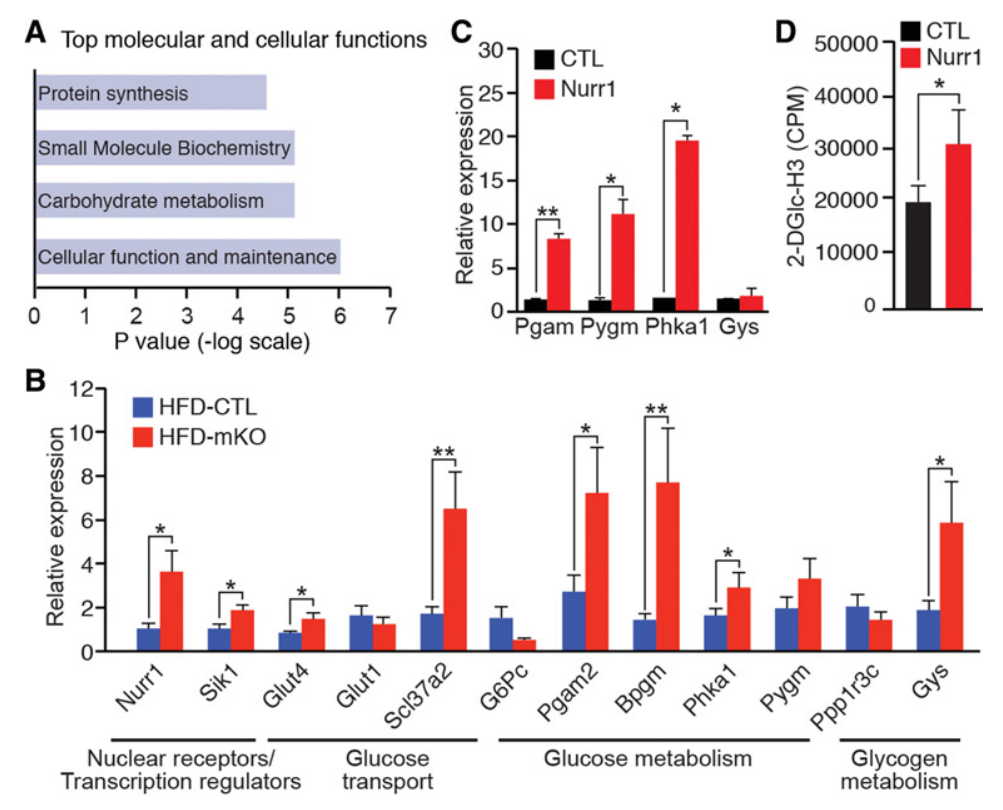

mean \pm SEM. $\left(^{*}\right) P<0.05 ;(* *) P<0.005$.
Figure 4. MED13 up-regulates Nurr1 expression and glucose-handling gene expression in skeletal muscle. Differentially expressed genes from Illumina RNA-seq analysis comparing RNA isolated from gastrocnemius muscle of 18-wk-old MED13-mKO and CTL mice after $12 \mathrm{wk}$ on their respective diets. (A) Ingenuity Pathway Analysis was used to reveal the top cellular and molecular networks. (B) RNA expression level of Nurr1, saltinducible kinase 1 (Sik1), and metabolic genes (glucose transporter member 4 [Glut4], glucose transporter member 1 [Glut1], solute carrier family 37 glucose6-phosphate transporter member 2 [S1c37a2], glucose 6-phosphatase c $[\mathrm{G} 6 \mathrm{Pc}]$, phosphoglycerate mutase 2 [Pgam2], 2,3-bisphosphoglycerate mutase [Bpgm], phosphorylase glycogen muscle [Pygm], phosphorylase kinase al [Phka1], protein phosphatase 1, regulatory subunit 3C $[P p p 1 r 3 c]$, and glycogen synthase [Gys]) measured by real-time qRT-PCR in gastrocnemius muscle from mice on a HFD for 8 wk. $n=8$. (C) Real-time qRT-PCR analysis of glycolytic genes (Pgam2, Pygm, and Phka1) expressed in $\mathrm{C} 2 \mathrm{C} 12$ myotubes infected with CTL retrovirus and retrovirus expressing Nurr1. (D) Glucose uptake in myotubes infected with CTL retrovirus and retrovirus expressing Nurr1. Data are represented as 
was also confirmed by Western blot analysis (Supplemental Fig. S13). Nurr1 belongs to a nuclear receptor family that contains three members (NR4A1/Nur77, NR4A2/ NURR1, and NR4A3/NOR-1). Nur77 and NOR-1 have been reported to be involved in muscle metabolism, but the function of NURR1 in skeletal muscle remains unknown (Chao et al. 2007, 2012; Pearen and Muscat 2012). To explore the potential effect on muscle metabolism, NURR1 was overexpressed in C2C12 muscle cells using retroviral transduction. NURR1 overexpression strongly induced genes involved in glucose and glycogen metabolism, such as Pgam, Pygm, and Phka1 (Fig. 4C), and increased glucose uptake into $\mathrm{C} 2 \mathrm{C} 12$ myotubes as measured by ${ }^{3} \mathrm{H}$-2-deoxyglucose uptake (Fig. 4D). These results indicate that genetic deletion of Med13 in muscle increases expression of NURR1, which in turn activates the expression of key genes involved in glucose metabolism.

Regulation of Glut4 transcription by NURR1, MEF2, and MED13

GLUT4, the main effector of insulin-stimulated glucose transport in skeletal muscle, was up-regulated in muscle from MED13-mKO mice on a HFD compared with CTL mice (Fig. 4B). To understand how MED13 regulates Glut4 expression, we analyzed the Glut4 promoter for functional regulatory elements and identified a consensus sequence for binding of NURR1 (referred to as a NURR1 response element [NRE]) adjacent to a binding site for MEF2 (MEF2 regulatory element [MRE]), shown previously to regulate the Glut4 promoter (Fig. 5A; Santalucía et al. 2001; Knight et al. 2003; Pei et al. 2006). Chromatin immunoprecipitation (ChIP) assays confirmed the occupancy of NRE and MRE sites by NURR1 and MEF2 proteins, respectively, in skeletal muscle (Fig. 5B).

NURR1 and MEF2 individually activated the Glut4 promoter linked to a luciferase reporter, and the combination of NURR1 and MEF2 resulted in synergistic activation of the Glut4 promoter (Fig. 5C). This synergistic effect was lost upon mutation of the NRE or MRE sites (Fig. 5C). MED13 expression significantly repressed the activation of the Glut4 promoter by MEF2 and NURR1 (Fig. 5C). Interestingly, mutation of the MRE in the Glut4 promoter strongly diminished activation by both MEF2 and NURR1. Similarly mutation of the NRE prevented activation by NURR1 and also affected MEF2 activation, suggesting cooperative transcriptional activation by the two factors. In light of their synergistic activation of the Glut4 promoter, we tested whether MEF2 and NURR1 interacted directly. Indeed, in coimmunoprecipitation /coIP) assays, the anti-Myc antibody specifically immunoprecipitated MEF2-Myc with Flag-tagged NURR1 (Fig. 5D).

We also identified a highly conserved MEF2 site in the Nurr1 cis-proximal enhancer region (Fig. 5E; Castillo et al. 1997; Saucedo-Cardenas et al. 1997). This site bound MEF2 in muscle cells, as shown by ChIP assay (Fig. 5F). The Nurr1 enhancer with the MRE linked to a luciferase reporter was activated by MEF2 (Fig. 5G). MED13 expres- sion significantly repressed the activation of the Nurr1 enhancer by MEF2 (Fig. 5G).

To investigate whether repression of the Glut4 promoter by MED13 occurred through a direct interaction with NURR1 or MEF2, we performed co-IP assays using GFPtagged MED13, Flag-tagged NURR1, and Myc-tagged MEF2. These experiments revealed direct association of MED13 with NURR1 (Fig. 5H) but not with MEF2 (Supplemental Fig. S14).

Genetic deletion of Med13 in muscle increases expression of NURR1 and glucose-handling genes such as Glut4 in response to a HFD. To determine whether muscle deletion of Med13 leads to increased occupancy of MEF2 and NURR1 with target sites associated with their respective target genes, we performed ChIP assays in skeletal muscle of CTL and MED13-mKO mice on a NC diet and HFD. ChIP-qPCR analysis of MEF2 and NURR1 binding showed similar binding to the Nurr1 and Glut4 genes in skeletal muscle of CTL mice on a NC diet compared with a HFD (Fig. 5I,K). Remarkably, ChIP-qPCR analysis of MEF2 and NURR1 binding to their target genes revealed increased binding in skeletal muscle of MED13mKO mice compared with CTL mice on a HFD (Fig. 5J, L). Overall, these results demonstrate that MED13 suppresses NURR1 expression and prevents activation of the Glut4 promoter by NURR1 and MEF2, thereby suppressing glucose utilization pathways in skeletal muscle.

\section{Discussion}

Our results uncover a new regulatory pathway for metabolic control and an unanticipated role of the Mediator subunit MED13 in the control of skeletal muscle metabolism and systemic energy homeostasis. The absence of MED13 in skeletal muscle results in enhanced glucose utilization and storage as glycogen, rendering skeletal muscle hyperresponsive to insulin under HFD conditions and thereby preventing fatty liver disease. Our results show that NURR1 acts downstream from MED13 in skeletal muscle to regulate expression of genes linked to glucose metabolism. The increase in NURR1 expression in MED13-mKO skeletal muscle provides a mechanistic basis for the enhanced glucose metabolism and the insulin sensitizer effect in these mutant mice.

\section{A metabolic gene circuit downstream from MED13}

Increased expression of Nurr1, Sik1, and glucose metabolic genes in MED13-mKO mice suggests a repressive function of MED13 under HFD-induced insulin-resistant conditions in skeletal muscle. These observations also imply that nutritional signals regulate MED13 function and, consequently, NURR1 and MEF2 activity. These observations are in agreement with a previous study that reported a decline in Nurr1 expression in skeletal muscle of mice on a HFD, suggesting that conditions of insulin resistance suppress its expression (Fu et al. 2007). Nurr1 has also been identified as one of the most up-regulated genes in human muscle biopsies after exercise /Catoire et al. 

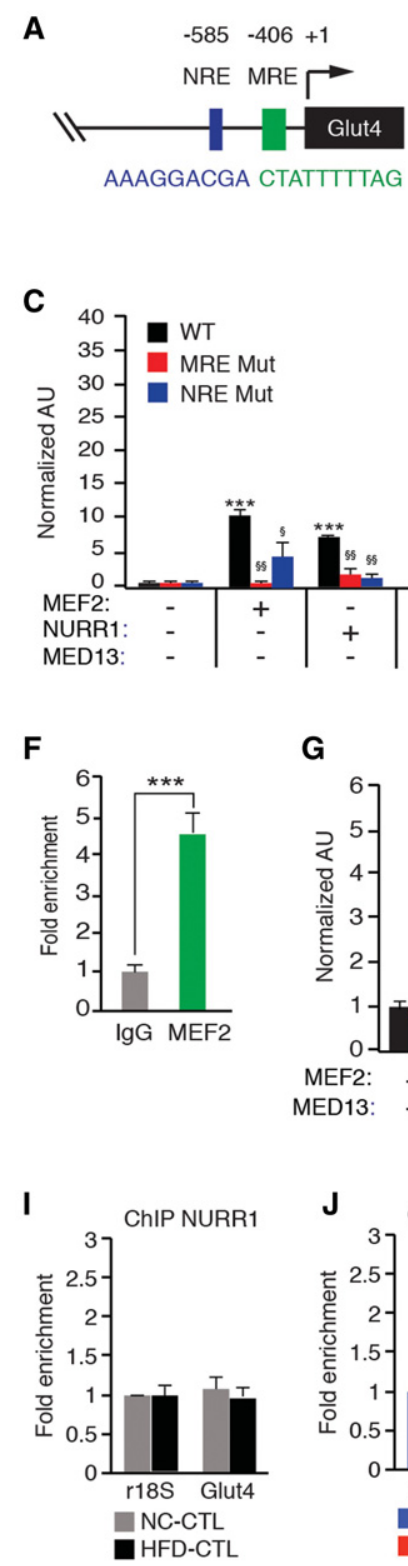
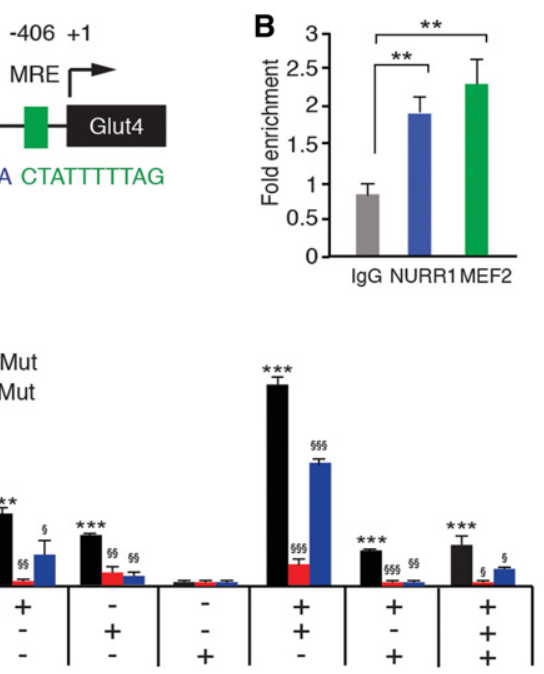
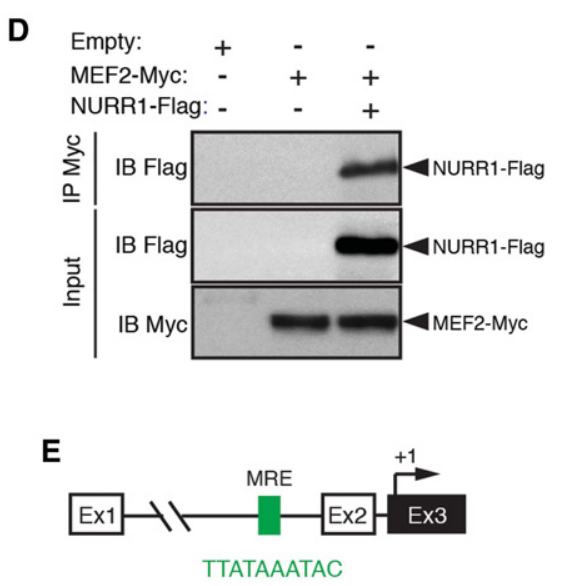

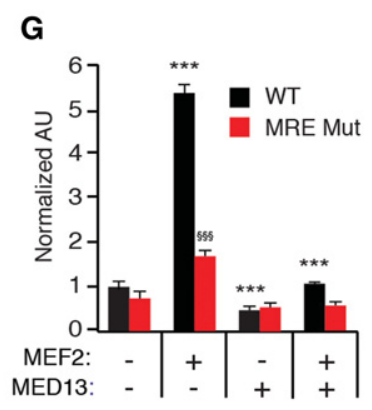

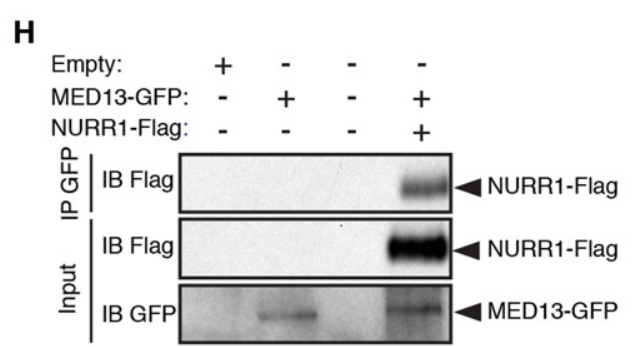

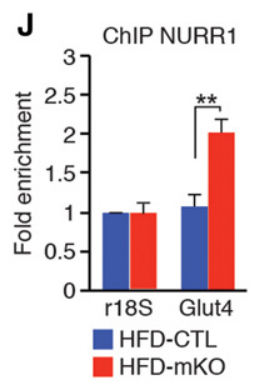

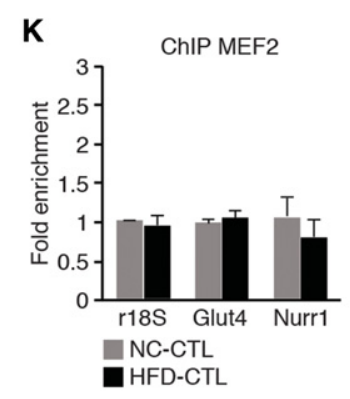

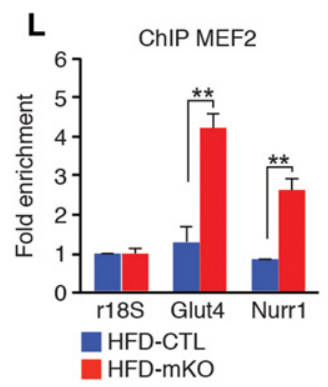

Figure 5. Regulation of the Glut4 and Nurr1 promoters. (A) Structure of the Glut4 promoter and sequences of NRE and MRE sites. (B) ChIP assays showing binding of NURR1 and MEF2 to the Glut4 promoter in mouse skeletal muscle. Antibodies against NURR1 and MEF2 were used in ChIP assays for the Glut4 promoter. Graphs display mean quantification of ChIP (percentage of input) normalized to IgG control. $n=3$. (C) Transcriptional activation of the Glut4 promoter linked to the luciferase reporter in COS7 cells by NURR1, MEF2, and MED13. Promoters with mutations in the NRE- and MRE-binding sites were also included as indicated. $(D)$ Coimmunoprecipitation (co-IP) experiments were performed by cotransfecting Myc-tagged MEF2 and Flag-tagged NURR1 in HEK293 cells. Antibodies against the Myc epitope were used for co-IP. The extracts (input) from HEK293 cells and the proteins from the immunoprecipitation were analyzed by immunoblotting (IB). Representative results for co-IP (repeated three times) are shown. (E) Schematic MRE site in the cis-proximal enhancer region of the Nurr1 gene. $(F)$ ChIP assays showing binding of MEF2 to the Nurr1 promoter in mouse skeletal muscle. Antibodies against MEF2 or IgG were used in ChIP assays for the Nurr1 promoter. Graphs display the mean quantification of ChIP (percentage of input) normalized to IgG control. $n=3 .(G)$ Transcriptional activation of the Nurr1 cis-proximal enhancer region linked to the luciferase reporter in COS7 cells by MEF2. A cis-proximal enhancer region with a mutation in the MRE site was also tested. (H) Co-IP experiments were performed by cotransfecting Flag-tagged Nurr1 and GFP-tagged Med13 in HEK293 cells. Antibodies against the GFP epitope were used for co-IP. The extracts (input) from HEK293 cells and the proteins from the immunoprecipitation were analyzed by immunoblotting (IB). Representative results for co-IP (repeated three times) are shown. $(I-L)$ ChIP assays showing binding of NURR1 and MEF2 to the Glut4 promoter and r18S gene in skeletal muscle of CTL and MED13-mKO mice on a NC diet and HFD, as indicated. Data are represented as mean \pm SEM. Significant differences between conditions are indicated by asterisks $([*] P<0.05$; $[* *]] P<0.005$; $\left.\left[{ }^{* * *}\right] P<0.0005\right)$, and significant differences in the same condition between wild-type constructs and mutants are indicated by double S $([\S] P<0.05 ;[\S \S] P<0.005 ;[\S \S \S] P<0.0005)$. 
2012). Although changes in expression of Nurr1 and the related nuclear receptors Nor-1 and Nur77 have been associated with changes in lipid, carbohydrate, and energy homeostasis (Chao et al. 2007, 2012; Pearen et al. 2012), the physiological significance of such changes was not previously established. Our study reveals for the first time the involvement of Nurr1 in skeletal muscle glucose metabolism and reveals the mechanistic basis for metabolic control by this orphan nuclear receptor.

Skeletal muscle deletion of MED13 and enhanced muscle glucose disposal affect the liver by preventing the development of hepatic steatosis. Analysis of several potential myokines, such as irisin, interleukin-6, and several members of the FGF family, showed no evidence for their involvement in signaling from muscle to the liver in response to skeletal muscle deletion of Med13. Numerous studies have uncovered the importance of myokines in the interorgan metabolic communication in the body; however, our results reveal a distinct mechanism for systemic metabolic control and prevention of hepatic steatosis as a result of an insulin-sensitizing effect generated by the muscle deletion of Med13.

Our results also identify MED13 as a repressor of a NURR1-MEF2 cooperative pathway that exerts transcriptional control of glucose handling in response to nutritional signals. MED13, NURR1, and MEF2 form an integrated feed-forward loop that couples transcriptional and post-translational controls to amplify the effects of nutritional stimuli such as a HFD on expression of Glut4 and other glucose-handling genes.

A model to account for our results is shown in Figure 6A. According to this model, MED13 represses the expression and activity of NURR1, which acts as an activator of Glut4 and other genes involved in glucose metabolism in muscle. The repressive influence of MED13 occurs through regulation of Nurr1 expression and also through a direct interaction with the NURR1 protein. In the absence of MED13, MEF2 activates Nurr1 transcription through an increased binding at the Nurr1 gene. Consequently, increased NURR1 expression activates Glut4 transcription. Additionally, our results suggest that MED13 represses expression of SIK1. Since SIK1 is a class II histone deacetylase kinase that enhances MEF2 activity, it is a good candidate for indirect regulation of MEF2 activity by MED13 (Berdeaux et al. 2007; Takemori et al. 2009). Several metabolic genes up-regulated in muscle of MED13-mKO mice on a HFD have been identified as direct targets of MEF2, including the genes encoding GLUT4 and members of the NR4A family (Blaeser et al. 2000; Youn and Liu 2000; Santalucía et al. 2001; Gray et al. 2002; Potthoff and Olson 2007). Therefore, MEF2 represents an important partner for MED13 in the transcriptional control of glucose handling in response to nutritional signals.

\section{Modulation of hepatic metabolism by skeletal muscle MED13}

Skeletal muscle deletion of Med13 and enhanced muscle glucose disposal affect the liver by preventing the develop- ment of hepatic steatosis. As to how the absence of MED13 in muscle evokes such remarkable effects on the liver, it is important to note that the liver and skeletal muscle share an intimate relationship with respect to glycemic control in the body. The liver is a pivotal site for nutritional adaptation, since it can store glucose (via glycogen synthesis and de novo lipogenesis), release glucose (via glycogenolysis and gluconeogenesis), or release lipid fuels (as lipoproteins) and is one of the first tissues to respond and adapt to nutritional changes (Ranalletta et al. 2007; Turner et al. 2013). We show that skeletal muscle lacking MED13 displays enhanced glucose uptake and disposal and stores the energy as glycogen. Muscle of MED13-mKO mice shows an approximately twofold increase in glycogen storage compared with CTL mice on a HFD. Skeletal muscle accounts for $40 \%$ of total body mass, which represents $70 \%-80 \%$ of total glycogen in the body. Therefore, a twofold increase in muscle glycogen content has a major impact on whole-body metabolism. These observations are in agreement with previous studies that reported enhanced glucose tolerance and insulin sensitivity in mice with a 1.3-fold increase of glycogen content in skeletal muscle due to enhanced glycogen synthesis (Patel et al. 2008). Similarly, skeletal muscle from transgenic mice overexpressing Glut4 shows an increase in glycogen content accompanied by enhanced glucose tolerance and insulin sensitivity (Liu et al. 1993). Although changes in expression of Glut4 and glycogen storage have been associated with enhanced glucose tolerance and insulin sensitivity, our study reveals for the first time the involvement of MED13 in skeletal muscle glucose metabolism and its impact on hepatic steatosis in the HFD-induced insulin-resistant state.

As depicted in Figure 6B, in the HFD-induced insulinresistant state, skeletal muscle loses the ability to remove glucose from the blood, which is therefore diverted to the liver for storage. Additionally, the increased insulin and glucose levels in the HFD-induced insulin-resistant state stimulate hepatic nutrient sensors to drive the expression of genes involved in lipogenesis. Increased glucose diversion from muscle to the liver and hyperinsulinemia provoke hepatic steatosis under HFD conditions. The insulin-sensitizing effect generated by Med13 deletion in skeletal muscle enhances systemic glucose disposal and storage and improves hyperinsulinemia, which is sensed primarily by the liver (Fig. 6C). Med13 deletion in skeletal muscle influences the liver in several ways. First, since skeletal muscle lacking MED13 processes glucose and stores it as glycogen, less glucose is diverted to the liver for lipid storage. Second, enhanced glucose uptake by skeletal muscle deficient in MED13 leads to a decrease in compensatory insulin secretion by the pancreas and a reduction of hyperinsulinemia. Combined, these two outcomes are sensed primarily by the liver nutrient sensors, leading to a decrease in TG accumulation and prevention from hepatic steatosis.

Despite preventing hepatic steatosis and improving glucose and insulin tolerance, deletion of Med13 in skeletal muscle does not impact whole-body adiposity. The block to hepatic steatosis, despite normal adiposity of MED13- 

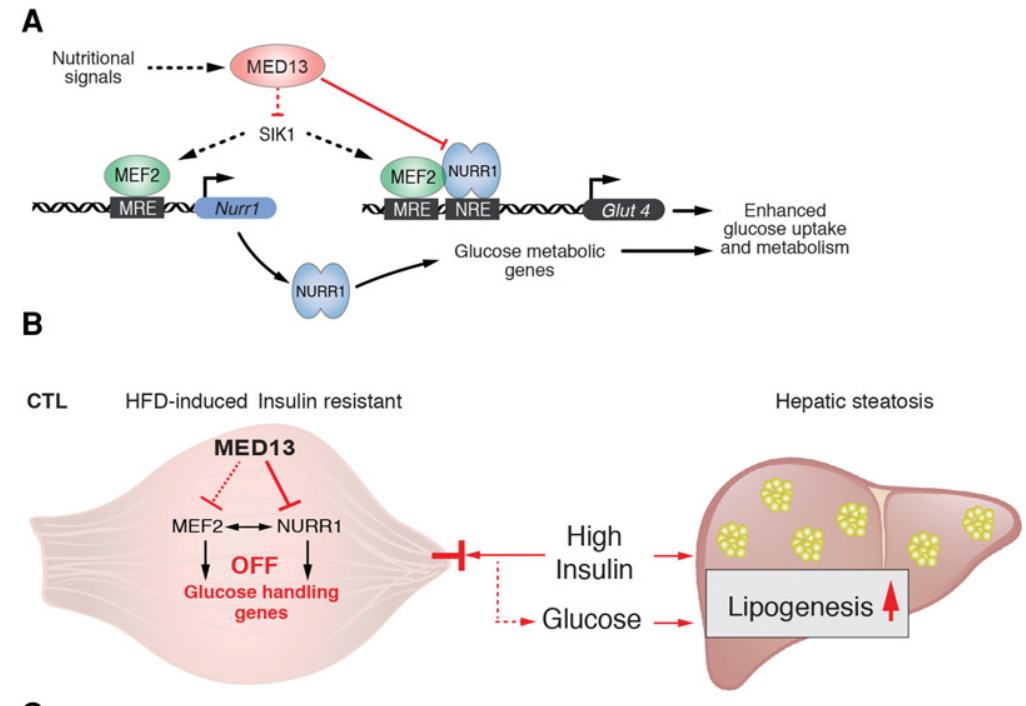

C

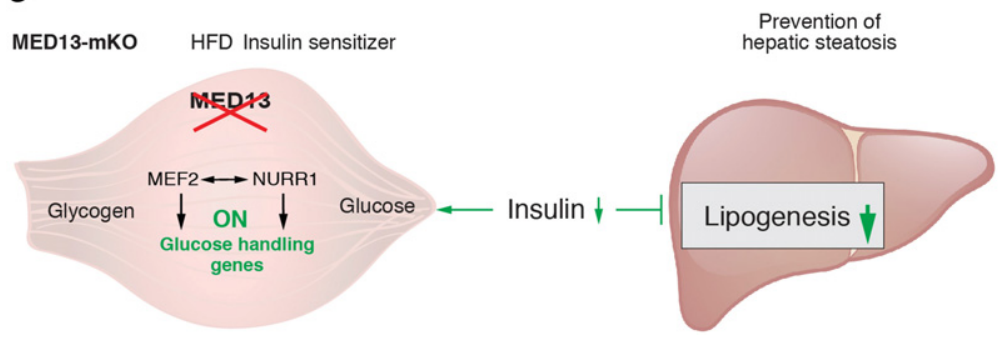

Figure 6. A model depicting MED13 regulation of NURR1-MEF2 activity and the influence of skeletal muscle MED13 on liver steatosis. (A) MED13 represses SIK1 expression, which allows activation of MEF2 and its target genes, including Nurr1. MED13 represses the expression and activity of Nurr1, which acts together with MEF2 as an activator of Glut4 and other genes involved in glucose metabolism in muscle. In the absence of MED13, MEF2 activates Nurr1 transcription. Consequently, increased NURR1 expression, together with MEF2, activates Glut4 transcription. $(B)$ In HFD-induced insulin resistance, insulin fails to promote muscle glucose uptake and disposal, therefore directing glucose to de novo lipogenesis in the liver. Increased insulin and glucose levels in the HFD-induced insulin-resistant state stimulate hepatic nutrient sensors to drive the expression of genes involved in de novo lipogenesis. Under HFD conditions, MED13 exerts a repressive effect on glucose handling genes through the NURR1/ MEF2 regulatory pathway. (C) Med13 deletion in skeletal muscle leads to an increase in the expression of glucose-handling genes and Nurr1 expression that generates an insulin-sensitizing effect with enhanced skeletal muscle glucose disposal and glycogen storage, which improves hyperinsulinemia. This effect is sensed primarily by the liver and influences it in two ways. First, since MED13-mKO skeletal muscle disposes of and stores glucose as glycogen, less glucose is diverted to the liver for lipid storage. Second, it leads to a decrease in compensatory insulin secretion by the pancreas followed by a reduction of hyperinsulinemia that results in decreased hepatic lipogenesis. Red arrows represent the processes occurring in CTL mice in HFD conditions. Green arrows represent the processes occurring in MED13-mKO mice in HFD conditions.

mKO mice, can be explained by the enhanced glucose disposal and glycogen storage in muscle without the increased expression of genes involved in lipid oxidation in muscle, the liver, or adipose tissues.

\section{Opposing metabolic functions of MED13 in skeletal muscle and the heart}

We showed previously that cardiac MED13 overexpression impacts systemic metabolism and enhances lipid oxidation and mitochondrial activity in WAT, BAT, and the liver (Grueter et al. 2012; Baskin et al. 2014). The findings of the present study reveal an antithetical function of MED13 in skeletal muscle, in which it suppresses glucose metabolism under conditions of HFD-induced insulin resistance. These observations suggest opposing metabolic functions of MED13 in cardiac and skeletal muscle tissues. It is believed that distinct Mediator subunits are recruited by different transcription factors, leading to genespecific physiological effects, including regulation of lipid metabolism and energy homeostasis. Previous studies have also suggested dual, opposing functions for another Mediator complex subunit, MED23, in regulating cytoskeletal and adipogenic gene programs (Yin et al. 2012). Our results show that the Mediator complex performs customized, tissue-specific functions in metabolic regulation by cardiac and skeletal muscle.
Skeletal muscle is a more glycolytic tissue than the heart, which is a predominantly oxidative metabolic tissue. Skeletal muscle represents $\sim 40 \%$ of body mass and accounts for $80 \%$ of glucose uptake in the body. Moreover, skeletal muscle and the liver display an active metabolic communication that mediates glycemic control in response to changing energy demands, which requires additional nutrition- and signal-sensing pathways that will allow rapid adaptation of skeletal muscle metabolism. MED13 appears to occupy a central role in the governance of these metabolic functions of skeletal muscle.

\section{Potential therapeutic implications}

Hepatic steatosis, resulting from metabolic syndrome and $\mathrm{T} 2 \mathrm{D}$, is the most common cause of chronic liver disease. The phenotype of mice with skeletal muscle-specific deletion of MED13 underscores the importance of this Mediator subunit in the control of glucose homeostasis, providing new insight into the molecular basis of the regulation of skeletal muscle glucose metabolism, which affects fatty liver disease, insulin resistance, and T2D. In this regard, future therapeutic strategies should take into account the possible opposing functions that agonist and antagonist drugs could exert on metabolic coactivators in different tissues. Further understanding of the various interactions between different activators and Mediator 
subunits in individual metabolic tissues may offer novel strategies to manipulate these diverse biological functions, which may represent a potential therapeutic inroad into the treatment of obesity and its associated diseases.

\section{Materials and methods}

\section{Animals}

Animals were housed in a pathogen-free barrier facility with a 12-h light/dark cycle and maintained on standard chow (2916 Teklad Global). Med13 ${ }^{\text {flox/flox }}$ mice were generated through homologous recombination (Grueter et al. 2012). Exons 7 and 8 of the Med13 gene were flanked by two loxP sites. The Med13 flox/flox mice were backcrossed with C57/BL6J mice for more than three generations. To inactivate MED13 in skeletal muscle, we crossed Med13 $3^{\text {flox } / \text { flox }}$ mice with Myo-Cre transgenic mice in the C57BL/6J genetic background (Li et al. 2005). The littermates were screened by genotyping, and mice with two copies of loxP sites and Cre recombinase were characterized as MED13$\mathrm{mKO}\left(\mathrm{Med} 13^{\text {flox/flox }} ;\right.$ Myo-Cre). Male mice were used in all experiments. For a HFD (60\% fat calories; Research Diet, D12492), mice were fed from the age of $5 \mathrm{wk}$ to the indicated times. Tissues were taken in the fed state except when otherwise mentioned.

\section{Study approval}

All experimental procedures involving animals in this study were reviewed and approved by the University of Texas Southwestern Medical Center's Institutional Animal Care and Use Committee.

\section{Plasmids}

DNA fragments from the promoter region of Glut4 and Nurr1 were isolated by PCR using mouse genomic DNA as a template and cloned into the luciferase reporter pGL3 (Promega). Mutagenesis of MEF2 and NRE sites was performed using the QuikChange II site-directed mutagenesis kit (Agilent Technologies) according to the manufacturer's instructions. The pcDNA3.1 Myc-based MEF2 expression vectors were reported previously (McKinsey et al. 2000). Primer sequences and plasmid construct designs are available on request. Plasmids encoding Nurr1 and Nur77 were obtained from the Invitrogen library.

\section{Antibodies}

Antibodies to MYH1 (1:3000; Noq7 and M8421; Sigma-Aldrich), NURR1 (1:1000; Abcam, ab41917), MEF2 (1:1000; Santa Cruz Biotechnology, sc-313), GFP (1:1000; Life Technology, A11122), Flag (1:1000; clone M2; Sigma-Aldrich), MYC (1:3000; clone 9E10; Sigma-Aldrich), and GAPDH (1:8000; Millipore, MAB374) and goat anti-mouse and goat-anti rabbit HRP-conjugated secondary antibodies (1:3000; Bio-Rad) were used for the described experiments.

\section{Retrovirus production and C2C12 infection}

Retrovirus production and $\mathrm{C} 2 \mathrm{C} 12$ myotube infection were performed as previously described (Millay et al. 2013). See the Supplemental Material for a more detailed protocol.

\section{RNA analysis}

RNA was isolated from mouse tissues using TRIzol reagent (Invitrogen). RT-PCR was performed to generate cDNA. Primers for ribosomal 18S RNA served as internal controls for the quality of RNA. The sequence of primers is available on request. Illumina RNA-seq analysis was performed by the University of Texas Southwestern Microarray Core Facility using RNA extracted from tissues of 12-wk-old CTL or MED13-mKO mice on a HFD or NC diet. See the Supplemental Material for a more detailed protocol.

\section{ChIP assays}

ChIP assays were performed as described previously by Tuteja et al. (2008). See the Supplemental Material for a more detailed protocol.

\section{Luciferase reporter assays}

Luciferase assays were performed as described previously (Grueter et al. 2012). See the Supplemental Material for a more detailed protocol.

\section{Immunoprecipitation}

HEK293 cells were grown in DMEM containing 10\% FBS. Transfections were performed with FuGENE 6 transfection reagent (Promega) according to the manufacturer's instructions. Twenty-four hours after transfection, the cells were lysed in lysis buffer (50 mM Tris at pH 7.5, $150 \mathrm{mM} \mathrm{NaCl}, 1 \%$ TritonX-100, Complete protease inhibitor cocktail [Roche], $1 \mathrm{mM}$ PMSF, $10 \mathrm{mM}$ $\mathrm{NaF}$ ) with a syringe and a Fischer Scientific 550 sonicator. For the co-IP analysis of NURR1 and MEF2 (using Flag-tagged NURR1 and Myc-tagged-MEF2), anti-MYC agarose beads (Sigma-Aldrich) were incubated with extract. The immunoprecipitated proteins were analyzed by immunoblotting. For the co-IP analysis of NURR1 and MED13 (using Flag-tagged NURR1 and GFP-tagged-MED13), $1 \mu \mathrm{g}$ of anti-GFP antibody was incubated with extract and Dynabeads protein G-conjugated magnetic beads (Life Technologies), and the immunoprecipitated proteins were analyzed by immunoblotting. All experiments were repeated at least twice.

\section{Histology}

WAT, BAT, and the liver were isolated and fixed in $4 \%$ paraformaldehyde (PFA) and processed for H\&E staining. For Oil Red O staining, liver tissues were fixed in 4\% PFA overnight and incubated in $12 \%$ sucrose for $12 \mathrm{~h}$ and then in $18 \%$ sucrose overnight before being cryoembedded and sectioned by the University of Texas Southwestern Histology Core Facility. For skeletal muscle fiber analysis, tissues were frozen in liquid nitrogen precooled isopentane, and 8 - $\mu \mathrm{m}$ sections were used for $H \& E$ and fiber type staining.

\section{Metabolic chambers and whole-body composition analysis}

Metabolic phenotyping of CTL and MED13-mKO mice on a HFD was performed using TSE metabolic chamber analysis by the Mouse Metabolic Phenotyping Core Facility at University of Texas Southwestern Medical Center. Thirteen-week-old mice on a HFD were placed in TSE metabolic chambers for an initial 5-d acclimation period followed by a $4.5-\mathrm{d}$ experimental period with data collection. Whole-body composition parameters were measured by magnetic resonance imaging (MRI) using a Bruker Minispec mq10 system.

\section{Plasma and tissue chemistry}

Blood was collected using a $1-\mathrm{mL}$ syringe coated in $0.5 \mathrm{M}$ $\mathrm{K}_{2}$ EDTA, and serum was collected by centrifugation at $1000 \mathrm{~g}$ 
for $20 \mathrm{~min}$. Insulin and leptin levels were measured by ELISA. Serum TG levels were measured using the Ortho Vitros 250 chemistry system. To measure TG in the liver and skeletal muscle, tissue specimens were frozen immediately after isolation and pulverized in liquid nitrogen with a cell crusher. Serum and tissue TG levels were measured by the Mouse Metabolic Phenotyping Core Facility at University of Texas Southwestern Medical Center.

\section{Muscle lipidomics analysis}

Lipids were quantified by shotgun lipidomics using an ABI $5600^{+}$ (AB Sciex). See the Supplemental Material for a more detailed protocol.

\footnotetext{
${ }^{13} \mathrm{C}$-glucose isotope metabolic tracing analysis
}

After a 6-h fast, mice underwent a glucose tolerance test in which $10 \%$ of $\left[\mathrm{U}_{-}{ }^{13} \mathrm{C}_{6}\right.$ ]-glucose $\left(99 \%\right.$ CLM-1396 D-Glc-U- ${ }^{13} \mathrm{C}_{6}$ from Cambridge Isotope) was administered via intraperitoneal injection. Tissues were collected at $60 \mathrm{~min}$ following glucose administration and rapidly frozen in liquid nitrogen. Glucose (Sunny and Bequette 2010), organic, and amino acid (Sobolevsky et al. 2003) ${ }^{13} \mathrm{C}$-mass isotopomer enrichments were determined as described previously. M+3 enrichments of tissue lactate and pyruvate and total mass enrichment of TCA cycle organic acids were used as semiquantitative indicators of glucose oxidation.

\section{Glucose uptake and insulin tolerance}

Glucose tolerance and insulin tolerance tests were performed as described previously (Grueter et al. 2012). See the Supplemental Material for a more detailed protocol.

\section{Glycogen measurements}

A glycogen colorimetric/fluorometric assay kit (Abcam, 65620) was used per the manufacturer's protocol to measure the quadricep glycogen content in CTL and MED13-mKO mice on a HFD and NC diet.

\section{Hyperinsulemic-euglycemic clamps}

Clamps were performed in conscious unrestrained animals as described previously (Ayala et al. 2006; Kim 2009). See the Supplemental Material for a more detailed protocol.

\section{Voluntary wheel running}

Ten-week-old MED13-mKO mice and corresponding CTL littermates were randomly assigned to housing in individual cages with or without a running wheel for a total of 6 wk. Completed wheel revolutions and time spent running were continuously monitored and recorded. Run distances over 24 -h periods were determined at the end.

\section{Treadmill exercise}

Mice were run on anExer-6 treadmill apparatus (Columbus Instruments) with mild electrical stimulus at $5 \%$ inclination. Two days before the experiment, mice were acclimatized to a single-lane treadmill by performing a $10-\mathrm{m} / \mathrm{min}$ run for $30 \mathrm{~min}$. To test maximal running speed, mice were acclimated for a period of $30 \mathrm{~min}$ at $10 \mathrm{~m} / \mathrm{min}$ followed by acceleration for $1 \mathrm{~m} / \mathrm{min}$ until exhaustion. For endurance tests, mice were acclimated for $60 \mathrm{~min}$ at $10 \mathrm{~m} / \mathrm{min}$ followed by incremental acceleration $(1 \mathrm{~m} / \mathrm{min}$ every $5 \mathrm{~min}$ ) to a maximum speed of $20 \mathrm{~m} / \mathrm{min}$ until exhaustion. Exhaustion was defined by failure to run for $>10 \mathrm{sec}$. Time to exhaustion was determined.

\section{Immunoblot analysis}

Proteins were extracted from skeletal muscle of mice. Muscles were homogenized in RIPA buffer, $10 \mathrm{mM} \mathrm{NaF}, 1 \mathrm{mM} \mathrm{Na}_{3} \mathrm{VO} 4$, $1 \mathrm{mM}$ PMSF, and protease inhibitor tablet (Roche Diagnostics). Protein concentration was determined using a BCA protein assay kit (Thermo Scientific), and lysates were analyzed by SDS-polyacrylamide gel electrophoresis and Western blot analysis on a PVDF membrane.

\section{Statistical analysis}

All values are given as mean standard error. Differences between two groups were assessed using unpaired two-tailed Student's $t$-tests. $P<0.05$ was regarded as significant. Statistical analysis was performed in Excel (Microsoft).

\section{Acknowledgments}

We thank John Shelton for help with histology. We thank Lillian B. Sutherland, Jose Cabrera, Cheryl Nolen, John McAnally, Alex Mireault, Evelyn Tennison, Stephen Johnson, Xiaorong Fu, Eric D. Berglund, Guosheng Liang, and Jennifer Brown for their assistance. We appreciate the services of the University of Texas Southwestern Mouse Metabolic Phenotyping Core Facility. This work was supported by grants from the National Institutes of Health (HL-077439, HL-111665, HL093039, DK-099653, DK-094973, and U01-HL-100401), Foundation Leducq Networks of Excellence, Cancer Prevention and Research Institute of Texas, and the Robert A. Welch Foundation (grant 1-0025 to E.N.O.).

\section{References}

Allen BL, Taatjes DJ. 2015. The Mediator complex: a central integrator of transcription. Nat Rev Mol Cell Biol 16: 155166.

Ayala JE, Bracy DP, McGuinness OP, Wasserman DH. 2006. Considerations in the design of hyperinsulinemic-euglycemic clamps in the conscious mouse. Diabetes 55: 390-397.

Baskin KK, Grueter CE, Kusminski CM, Holland WL, Bookout AL, Satapati S, Kong YM, Burgess SC, Malloy CR, Scherer $\mathrm{PE}$, et al. 2014. MED13-dependent signaling from the heart confers leanness by enhancing metabolism in adipose tissue and liver. EMBO Mol Med 6: 1610-1621.

Belakavadi M, Fondell JD. 2010. Cyclin-dependent kinase 8 positively cooperates with mediator to promote thyroid hormone receptor-dependent transcriptional activation. Mol Cell Biol 30: 2437-2448.

Berdeaux R, Goebel N, Banaszynski L, Takemori H, Wandless T, Shelton GD, Montminy M. 2007. SIK1 is a class II HDAC kinase that promotes survival of skeletal myocytes. Nat Med 13: 597-603.

Blaeser F, Ho N, Prywes R, Chatila TA. 2000. $\mathrm{Ca}^{2+}$-dependent gene expression mediated by MEF2 transcription factors. $I$ Biol Chem 275: 197-209.

Brown MS, Goldstein JL. 2008. Selective versus total insulin resistance: a pathogenic paradox. Cell Metab 7: 95-96.

Buque X, Martinez MJ, Cano A, Miquilena-Colina ME, GarciaMonzon C, Aspichueta P, Ochoa B. 2010. A subset of 
dysregulated metabolic and survival genes is associated with severity of hepatic steatosis in obese Zucker rats. J Lipid Res 51: 500-513.

Castillo SO, Xiao Q, Lyu MS, Kozak CA, Nikodem VM. 1997. Organization, sequence, chromosomal localization, and promoter identification of the mouse orphan nuclear receptor Nurr1 gene. Genomics 41: 250-257.

Catoire M, Mensink M, Boekschoten MV, Hangelbroek R, Müller M, Schrauwen P, Kersten S. 2012. Pronounced effects of acute endurance exercise on gene expression in resting and exercising human skeletal muscle. PLoS One 7: e51066.

Chao LC, Zhang Z, Pei L, Saito T, Tontonoz P, Pilch PF. 2007. Nur77 coordinately regulates expression of genes linked to glucose metabolism in skeletal muscle. Mol Endocrinol 21: 2152-2163.

Chao LC, Wroblewski K, Ilkayeva OR, Stevens RD, Bain J, Meyer GA, Schenk S, Martinez L, Vergnes L, Narkar VA, et al. 2012. Skeletal muscle Nur77 expression enhances oxidative metabolism and substrate utilization. J Lipid Res 53: 2610-2619.

Chen W, Zhang X, Birsoy K, Roeder RG. 2010. A muscle-specific knockout implicates nuclear receptor coactivator MED1 in the regulation of glucose and energy metabolism. Proc Natl Acad Sci 107: 10196-10201.

Choi SH, Ginsberg HN. 2011. Increased very low density lipoprotein (VLDL) secretion, hepatic steatosis, and insulin resistance. Trends Endocrinol Metab 22: 353-363.

Chu Y, Rosso LG, Huang P, Wang Z, Xu Y, Yao X, Bao M, Yan J, Song H, Wang G. 2014. Liver Med23 ablation improves glucose and lipid metabolism through modulating FOXO1 activity. Cell Res 24: 1250-1265.

Denechaud P-D, Bossard P, Lobaccaro J-MA, Millatt L, Staels B, Girard J, Postic C. 2008. ChREBP, but not LXRs, is required for the induction of glucose-regulated genes in mouse liver. $I$ Clin Invest 118: 956-964.

Egan B, Zierath JR. 2013. Exercise metabolism and the molecular regulation of skeletal muscle adaptation. Cell Metab 17: 162-184.

Fu Y, Luo L, Luo N, Zhu X, Garvey WT. 2007. NR4A orphan nuclear receptors modulate insulin action and the glucose transport system: potential role in insulin resistance. I Biol Chem 282: 31525-31533.

Furumoto T, Tanaka A, Ito M, Malik S, Hirose Y, Hanaoka F, Ohkuma Y. 2007. A kinase subunit of the human mediator complex, CDK8, positively regulates transcriptional activation. Genes Cells 12: 119-132.

Gray S, Feinberg MW, Hull S, Kuo CT, Watanabe M, Sen-Banerjee S, DePina A, Haspel R, Jain MK. 2002. The Krüppel-like factor KLF15 regulates the insulin-sensitive glucose transporter GLUT4. J Biol Chem 277: 34322-34328.

Grueter CE, van Rooij E, Johnson BA, DeLeon SM, Sutherland LB, Qi X, Gautron L, Elmquist JK, Bassel-Duby R, Olson EN. 2012. A cardiac microRNA governs systemic energy homeostasis by regulation of MED13. Cell 149: 671-683.

Inoue $\mathrm{M}$, Ohtake $\mathrm{T}$, Motomura $\mathrm{W}$, Takahashi $\mathrm{N}$, Hosoki $\mathrm{Y}$, Miyoshi S, Suzuki Y, Saito H, Kohgo Y, Okumura T. 2005. Increased expression of PPAR $\gamma$ in high fat diet-induced liver steatosis in mice. Biochem Biophys Res Commun 336: 215-222.

Izumiya Y, Hopkins T, Morris C, Sato K, Zeng L, Viereck J, Hamilton JA, Ouchi N, LeBrasseur NK, Walsh K. 2008. Fast/glycolytic muscle fiber growth reduces fat mass and improves metabolic parameters in obese mice. Cell Metab 7: 159-172.

Jia Y, Viswakarma N, Reddy JK. 2014. Med1 subunit of the mediator complex in nuclear receptor-regulated energy metabo- lism, liver regeneration, and hepatocarcinogenesis. Gene Expr 16: 63-75.

Kim JK. 2009. Hyperinsulinemic-euglycemic clamp to assess insulin sensitivity in vivo. Methods Mol Biol 560: 221-238.

Knight JB, Eyster CA, Griesel BA, Olson AL. 2003. Regulation of the human GLUT4 gene promoter: interaction between a transcriptional activator and myocyte enhancer factor $2 \mathrm{~A}$. Proc Natl Acad Sci 100: 14725-14730.

Kornberg RD. 2005. Mediator and the mechanism of transcriptional activation. Trends Biochem Sci 30: 235-239.

Li S, Czubryt MP, McAnally J, Bassel-Duby R, Richardson JA, Wiebel FF, Nordheim A, Olson EN. 2005. Requirement for serum response factor for skeletal muscle growth and maturation revealed by tissue-specific gene deletion in mice. Proc Natl Acad Sci 102: 1082-1087.

Liu ML, Gibbs EM, McCoid SC, Milici AJ, Stukenbrok HA, McPherson RK, Treadway JL, Pessin JE. 1993. Transgenic mice expressing the human GLUT4/muscle-fat facilitative glucose transporter protein exhibit efficient glycemic control. Proc Natl Acad Sci 90: 11346-11350.

Malik S, Roeder RG. 2010. The metazoan Mediator co-activator complex as an integrative hub for transcriptional regulation. Nat Rev Genet 11: 761-772.

McKinsey TA, Zhang CL, Olson EN. 2000. Activation of the myocyte enhancer factor-2 transcription factor by calcium/calmodulin-dependent protein kinase-stimulated binding of 14-3-3 to histone deacetylase 5. Proc Natl Acad Sci 97: 14400-14405.

Meng Z-X, Li S, Wang L, Ko HJ, Lee Y, Jung DY, Okutsu M, Yan Z, Kim JK, Lin JD. 2013. Baf60c drives glycolytic metabolism in the muscle and improves systemic glucose homeostasis through Deptor-mediated Akt activation. Nat Med 19: 640-645.

Millay DP, O'Rourke JR, Sutherland LB, Bezprozvannaya S, Shelton JM, Bassel-Duby R, Olson EN. 2013. Myomaker is a membrane activator of myoblast fusion and muscle formation. Nature 499: 301-305.

Moon Y-A, Liang G, Xie X, Frank-Kamenetsky M, Fitzgerald K, Koteliansky V, Brown MS, Goldstein JL, Horton JD. 2012. The Scap/SREBP pathway is essential for developing diabetic fatty liver and carbohydrate-induced hypertriglyceridemia in animals. Cell Metab 15: 240-246.

Mootha VK, Lindgren CM, Eriksson K-F, Subramanian A, Sihag S, Lehar J, Puigserver P, Carlsson E, Ridderstråle M, Laurila E, et al. 2003. PGC-1 $\alpha$-responsive genes involved in oxidative phosphorylation are coordinately downregulated in human diabetes. Nat Genet 34: 267-273.

Oosterveer MH, Schoonjans K. 2013. Hepatic glucose sensing and integrative pathways in the liver. Cell Mol Life Sci 71: 1453-1467.

Patel S, Doble BW, MacAulay K, Sinclair EM, Drucker DJ, Woodgett JR. 2008. Tissue-specific role of glycogen synthase kinase $3 \beta$ in glucose homeostasis and insulin action. Mol Cell Biol 28: 6314-6328.

Pearen MA, Muscat GEO. 2012. Orphan nuclear receptors and the regulation of nutrient metabolism: understanding obesity. Physiology 27: 156-166.

Pearen MA, Eriksson NA, Fitzsimmons RL, Goode JM, Martel N, Andrikopoulos S, Muscat GEO. 2012. The nuclear receptor, Nor-1, markedly increases type II oxidative muscle fibers and resistance to fatigue. Mol Endocrinol 26: 372-384.

Pei L, Waki H, Vaitheesvaran B, Wilpitz DC, Kurland IJ, Tontonoz P. 2006. NR4A orphan nuclear receptors are transcriptional regulators of hepatic glucose metabolism. Nat Med 12: 1048-1055. 
Potthoff MJ, Olson EN. 2007. MEF2: a central regulator of diverse developmental programs. Development 134: 4131-4140.

Ranalletta M, Du XQ, Seki Y, Glenn AS, Kruse M, Fiallo A, Estrada I, Tsao TS, Stenbit AE, Katz EB, et al. 2007. Hepatic response to restoration of GLUT4 in skeletal muscle of GLUT4 null mice. Am I Physiol Endocrinol Metab 293: E1178-E1187.

Santalucía T, Moreno H, Palacín M, Yacoub MH, Brand NJ, Zorzano A. 2001. A novel functional co-operation between MyoD, MEF2 and TRa1 is sufficient for the induction of GLUT4 gene transcription. J Mol Biol 314: 195-204.

Saucedo-Cardenas O, Kardon R, Ediger TR, Lydon JP, Conneely OM. 1997. Cloning and structural organization of the gene encoding the murine nuclear receptor transcription factor, NURR1. Gene 187: 135-139.

Sobolevsky TG, Revelsky AI, Miller B, Oriedo V, Chernetsova ES, Revelsky IA. 2003. Comparison of silylation and esterification/acylation procedures in GC-MS analysis of amino acids. J Sep Sci 26: 1474-1478.

Sunny NE, Bequette BJ. 2010. Gluconeogenesis differs in developing chick embryos derived from small compared with typical size broiler breeder eggs. J Anim Sci 88: 912-921.

Taatjes DJ. 2010. The human Mediator complex: a versatile, genome-wide regulator of transcription. Trends Biochem Sci 35: 315-322.

Takemori H, Katoh Hashimoto Y, Nakae J, Olson EN, Okamoto M. 2009. Inactivation of HDAC5 by SIK1 in AICAR-treated C2C12 myoblasts. Endocr J 56: 121-130.
Tsai K-L, Sato S, Tomomori-Sato C, Conaway RC, Conaway JW, Asturias FJ. 2013. A conserved Mediator-CDK8 kinase module association regulates Mediator-RNA polymerase II interaction. Nat Struct Mol Biol 6: 611-619.

Turner N, Kowalski GM, Leslie SI, Risis S, Yang C, Lee-Young RS, Babb JR, Meikle PJ, Lancaster GI, Henstridge DC, et al. 2013. Distinct patterns of tissue-specific lipid accumulation during the induction of insulin resistance in mice by highfat feeding. Diabetologia 56: 1638-1648.

Tuteja G, Jensen ST, White P, Kaestner KH. 2008. Cis-regulatory modules in the mammalian liver: composition depends on strength of Foxa2 consensus site. Nucleic Acids Res 36: 4149-4157.

Yang F, Vought BW, Satterlee JS, Walker AK, Jim Sun ZY, Watts JL, DeBeaumont R, Mako Saito R, Hyberts SG, Yang S, et al. 2006. An ARC/Mediator subunit required for SREBP control of cholesterol and lipid homeostasis. Nature 442: 700-704.

Yin JW, Liang Y, Park JY, Chen D, Yao X, Xiao Q, Liu Z, Jiang B, Fu $\mathrm{Y}$, Bao M, et al. 2012. Mediator MED23 plays opposing roles in directing smooth muscle cell and adipocyte differentiation. Genes Dev 26: 2192-2205.

Youn HD, Liu JO. 2000. Cabin1 represses MEF2-dependent Nur77 expression and T cell apoptosis by controlling association of histone deacetylases and acetylases with MEF2. Immunity 13: 85-94.

Zhao J, Ramos R, Demma M. 2012. CDK8 regulates E2F1 transcriptional activity through S375 phosphorylation. Oncogene 32: 3520-3530. 


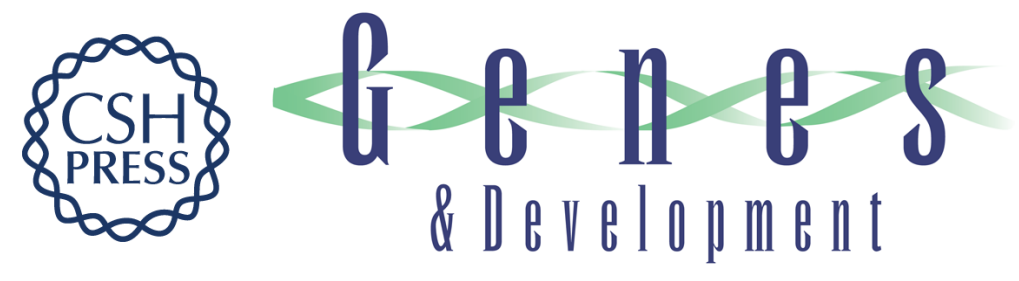

\section{A MED13-dependent skeletal muscle gene program controls systemic glucose homeostasis and hepatic metabolism}

Leonela Amoasii, William Holland, Efrain Sanchez-Ortiz, et al.

Genes Dev. 2016, 30:

Access the most recent version at doi:10.1101/gad.273128.115

\section{Supplemental http://genesdev.cshlp.org/content/suppl/2016/02/16/30.4.434.DC1 \\ Material}

References This article cites 55 articles, 16 of which can be accessed free at: http://genesdev.cshlp.org/content/30/4/434.full.html\#ref-list-1

Creative This article is distributed exclusively by Cold Spring Harbor Laboratory Press for the first Commons six months after the full-issue publication date (see

License http://genesdev.cshlp.org/site/misc/terms.xhtml). After six months, it is available under a Creative Commons License (Attribution-NonCommercial 4.0 International), as described at http://creativecommons.org/licenses/by-nc/4.0/.

Email Alerting Receive free email alerts when new articles cite this article - sign up in the box at the top Service right corner of the article or click here.

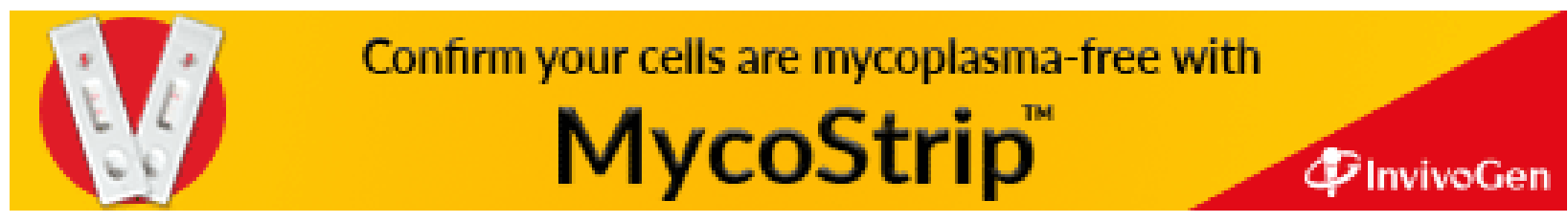

